\title{
Efecto del amamantamiento restringido en los conteos de células somáticas en vacas holstein cruzadas
}

\section{Effect of restricted suckling on somatic cell counts in cross holstein cows}

Roy Andrade B, ${ }^{1}$ Ph.D, Martin Pulido M, ${ }^{2}$ Esp, Diana Molano P, ${ }^{3}$ MVZ.

\begin{abstract}
1,2Universidad Pedagógica y Tecnológica de Colombia, Escuela de Medicina Veterinaria y Zootecnia, Facultad de Ciencias Agropecuarias, grupo de investigación GIDIMEVETZ. Tunja - Colombia. ${ }^{3}$ Universidad Pedagógica y Tecnológica de Colombia. * Correspondencia: royjandrade@yahoo.com
\end{abstract}

Recibido: Junio 23 de 2009; Aceptado: Abril 28 de 2010.

\section{RESUMEN}

Objetivo. Valorar el efecto del amamantamiento restringido en los conteos de células somáticas (CCS) en vacas Holstein Friesian cruzadas. Materiales y métodos. La zona de estudio está localizada en el Valle de Cuche municipio de Santa Rosa de Viterbo (Boyacá- Colombia). La muestra experimental se conformó de 20 vacas primíparas y 20 vacas multíparas en un $75 \%$ y $87.5 \%$ de pureza Holstein Friesian, las cuales fueron agrupadas de acuerdo al número de lactancias. Se dividió la población de estudio en dos unidades experimentales; en una unidad se realizó ordeño mecánico y amamantamiento de las crías (AR) y en la otra se hizo ordeño mecánico sin amamantamiento de las crías (CA), el amamantamiento se efectuó desde el día 4 hasta el 84 de edad de las crías para ambos sistemas. El experimento se realizó de enero de 2008 a Octubre de 2008, comenzando el día 4 posparto hasta el final de la lactancia. Resultados. La incidencia de los casos de mastitis de vacas fueron de 17.5 para CA y $6.25 \%$ para AR. El efecto entre el sistema crianza y la semana de lactación en CCS es altamente significativa $(p<0.001)$, en CA las vacas mostraron valores de significancia mayores $(p<0.001)$ comparados con las vacas asignadas al tratamiento de AR durante las semanas 2-14 de lactación. Conclusiones. El sistema de amamantamiento restringido disminuye significativamente los conteos de células somáticas y mejora sustancialmente la sanidad de la ubre.

Palabras clave: Lactación, vacas, proteínas, amamantamiento restringido. 


\section{ABSTRACT}

Objective. To assess the effect of restricted suckling on somatic cell counts (SCC) in Holstein Friesian crossed. Materials and methods. The study area is located in the Valley of Cuche municipality of Santa Rosa de Viterbo (Boyaca, Colombia). The experimental sample was formed of 20 primiparous cows and 20 multiparous cows by $75 \%$ and $87.5 \%$ pure Holstein Friesian, which were grouped according to the number of lactations. The study population was divided in two experimental units. In one unit was realized the mechanic milking, and the brooding nourishment $A R$, and in another one was made using mechanic milking, without brooding nourishment CA. The nourishment was made since the 4th day unit the 84th day of the brooding age for both systems. The experiment was carried out since January 2008 until October 2008, beginning the fourth day after birth, until the end of the lactation Results. The incidence of mastitis cows was 17.5 for CA and $6.25 \%$ for AR. The effect between breeding system and the lactation period in CCS is highly significant $(p<0.001)$, CA cows showed higher values of significance $(p<0.001)$ compared to cows assigned to the treatment of RA during weeks 2 - 14 of lactation. Conclusions. The restricted suckling system significantly lower somatic cell counts and substantially improves the health of the udder.

Key words: Lactation, cows, proteins, restricted suckling.

\section{NTRODUCCI ÓN}

La mastitis es una de las enfermedades más costosas que afectan los hatos lecheros en Colombia. El conteo de células somáticas (CCS) es usado como un indicador de sanidad de la ubre; por lo cual, los cuartos con conteos de 200.000 células/ml se consideran infectados, aunque esto no concuerda exactamente entre la incidencia de mastitis y los CCS. Por otro lado, la Federación Internacional de Lechería (1) recomienda un conteo de $500.000 \mathrm{cel} / \mathrm{ml}$, mientras que el estándar Europeo para leche cruda es de $400.000 \mathrm{cel} / \mathrm{ml}$ en CCS como indicador de mastitis.

La infección de la glándula mamaria es el resultado del daño del tejido y la disminución en la capacidad de sintetizar enzimas en las células secretoras de la síntesis de lactosa (2). La lactosa es retenida en las vesículas secretoras (3) causando diferencias de presión osmótica entre estas vesículas y el citoplasma celular. Se han reportado disturbios en la secreción como indicativo de la disminución de la leche producida en cuartos (4), que en las muestras de leche, los conteos de células somáticas se excedían desde 100.000 hasta 150.000 células por mililitro. Si el proceso inflamatorio persiste la involución de los lóbulos conduce como resultado a la obstrucción del ducto. Similarmente, cuando se examina diariamente los CCS se encuentran cambios a través de la producción, la edad de la cría, el hato, meses posparto, temporada, y la duración de la lactancia (5).

El objetivo de este estudio fue valorar el efecto del amamantamiento restringido en los conteos de células somáticas en vacas Holstein cruzadas.

\section{MATERI ALES Y MÉTODOS}

Zona de estudio y selección de la finca. Localizado en el Valle de Cuche; el municipio de Santa Rosa de Viterbo (BoyacáColombia), se encuentra a 2800 msnm, 72 grados, 56 minutos de longitud de Greenwich, con una temperatura promedio anual de $13^{\circ} \mathrm{C}$. Las precipitaciones a través del año son fuertes, pero dependen de la dirección e intensidad del viento. Cada año hay dos periodos de lluvias, el primero entre los meses de abril, mayo y comienzos de junio y el segundo entre octubre y noviembre. Se eligió una finca lechera, la cual se dividió en dos unidades experimentales. En la primera unidad se hizo ordeño con maquina y amamantamiento de las crías; y en la otra 
unidad se realizó ordeño con maquina y sin amamantamiento de crías. Las unidades experimentales se conformaron por un total de 20 vacas primíparas y 20 vacas multíparas de la raza Holstein Friesian en un $75 \%$ y $87.5 \%$ de pureza respectivamente; estas vacas y crías fueron agrupadas de acuerdo al número de lactancias. El experimento se realizó de enero 1 de 2008 a octubre 31 de 2008. El experimento inició a partir del día 4 posparto hasta el final de la lactancia; esta fue determinada individualmente con un mínimo de producción de leche de $2 \mathrm{~kg} /$ día, acordado con anterioridad. La duración de la lactancia varió entre 250 y 380 días.

\section{Recolección de los datos, conformación} de grupos experimentales y manejo de los animales. Las vacas fueron agrupadas en dos experimentos factoriales: un factor de manejo de amamantamiento de crías y un número de partos (numero de lactancias) de las vacas. Los dos niveles de amamantamiento de crías fueron: 1 . Amamantamiento de crías (crianza artificial, alimentación con leche dos veces al día, amamantamiento desde los 4 hasta los 84 días de edad, CA) y 2. Amamantamiento restringido (se les dejó mamar 5-10 minutos) después fueron retiradas del ordeño y volvieron a mamar después del ordeño hasta las 11 a.m., posteriormente se retiraron. Se hicieron amamantamientos desde los 4 hasta los 84 días de edad, AR). Los ordeños se realizaron dos veces al día; además se hicieron tres grupos de lactancia: 1 . Novillas de primer parto o vacas en primera lactancia (primíparas), (Total 20). 2. Vacas de segunda lactancia (Total 8). 3. Vacas de más de tres lactancias (Total 12). Todas las vacas fueron ordeñadas después de tres horas posparto y dos veces al día hasta el final de la lactancia; en los primeros tres días las crías mamaron libremente. Después del cuarto día de lactancia las vacas fueron ordeñadas mecánicamente dos veces al día empezando a las 4:00 a.m., los pezones fueron lavados y desinfectados de acuerdo al protocolo establecido en la finca. Para los análisis respectivos, se recolectó dos veces al mes $100 \mathrm{ml}$ de leche. Las muestras de leche se tomaron en tres momentos: Primera muestra de leche (PM) colectada antes de mamar y después de limpiar. Segunda muestra (SM) colectada después de mamar y antes de ordeñar. Tercera muestra (TM) colectada después del ordeño. Las muestras fueron analizadas en el laboratorio de leches de la UPTC con un Fossomatic Milkoscan. Las vacas fueron pesadas y la condición corporal evaluada cada dos semanas, después y antes del pastoreo.

Análisis de los datos. Se realizó estadística descriptiva, para la cual; los datos fueron agrupados de acuerdo al número de partos y porcentaje genético, debido a que el número de partos no presentaban el mismo porcentaje genético; formando 10 grupos por la combinación de estas dos variables en cada sistema.

Se realizó un análisis de CCS para sistema mes y otro para sistema - parto - porcentaje genético. Para evaluar las comparaciones se utilizó análisis de varianza multifactorial con un $95 \%$ de confianza y un margen de error de $0.05 \%$, complementado con análisis de conglomerados y a fin de analizar el comportamiento de las variables.

\section{RESULTADOS}

Los análisis de varianza mostrron significancias altas influenciadas por efectos principales y la interacción de los efectos como sistema de crianza, numero de parto de la vacas, HF proporción genética, temporada de nacimiento de las crías, cuarto de la ubre, semana de lactación, efecto de la interacción entre el sistema de cría y semana de lactación en los CCS durante las semanas 2-36 de lactación. El modelo matemático explicó el 39\% de variación en CCS con CV de 15.77 \% . 160 cuartos de 40 vacas fueron estudiados para Conteo de Células Somáticas (CCS) desde la segunda semana posparto hasta la semana 36 de lactación. La distribución de los casos de mastitis clínica y de cuartos durante los días 4-252 de lactación mostraron una incidencia de de 17.5 y $6.25 \%$ respectivamente; en los cuartos izquierdos se observó más incidencia de mastitis clínica que en los cuartos derechos.

Considerando la influencia de los principales 
efectos en el porcentaje de CCS de la leche, la interacción entre el sistema crianza y la semana de lactación en CCS fue altamente significativa $(p<0.001)$ (Figura 1$)$. Durante la lactancia temprana las vacas asignadas al tratamiento de AR; fueron mamadas por sus crías durante 5-10 minutos antes del ordeño, pero las vacas establecidas al tratamiento de CA no amamantaron sus crías. Las sesiones de amamantamiento se dieron hasta el día 84 de lactación; en CA las vacas mostraron valores de significancia mayores $(p<0.001)$ comparados con las vacas asignadas al tratamiento de AR durante las semanas 2-14 de lactación. De ahí en adelante el modelo de los CCS se alteró en ambos tratamientos y no se encontraron diferencias significativas durante las semanas 16-36 de lactancia.

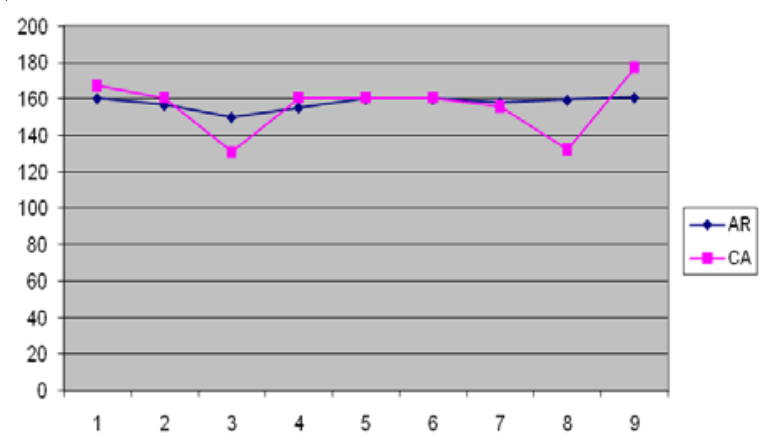

Figura 1. Análisis de ccs en relacion al sistema de crianza.

Como se esperaba, el número de parto de las vacas ejerce un efecto de mayor significancia $(p<=0.001)$ en el CCS. Las vacas multíparas exceden significativamente a las vacas primíparas en el CCS en un $18.01 \%$. Es interesante que HF mejoró significativamente $(p<0.001)$ disminuyendo los CCS. Vacas con proporción genética $87.5 \%$ HF mostraron específicamente menores CCS $(p<0.001)$ que HF $75.0 \%$ en $2.31 \%$.

En relación a la temporada de nacimientos; esta afectó significativamente los CCS $(p<0.001)$ durante el periodo estudiado (Figura 2 ). Las vacas cuyas crías nacieron en temporadas de lluvias mostraron altos CCS comparadas con vacas cuyas crías nacieron en época seca $(+1.72 \%)$. La posición del cuarto también tuvo un mayor valor de significancia $(p<0.001)$, influenciando el valor de CCS en las vacas. Se encontró que los

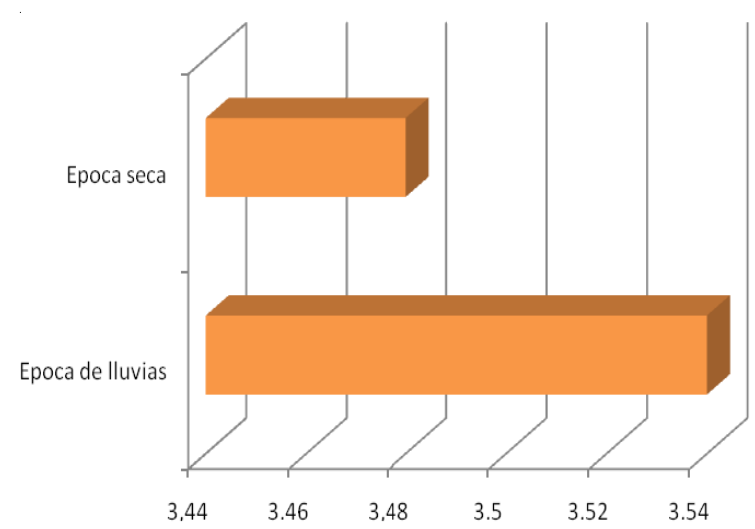

Figura 2. Relación del CCS con respecto a la temporada de nacimientos de las crías.

cuartos derechos posteriores tuvieron bajas prevalencias 3.33, mientras que los otros tuvieron valores en rangos desde 3.55 hasta 3.60 .

La semana de lactación representó igualmente un valor significativo $(p<0.001)$ afectando el CCS durante las semanas 2-36 de lactación. La alteración en los modelos del CCS fue similar al modelo del cambio de los componentes de la leche: altos CCS fueron encontrados en la lactancia temprana (semanas 2-4), mientras que el periodo después del pico de lactancia hasta la lactación tardía (semanas 16-36) bajaron los conteos.

La correlación entre el CCS y el porcentaje de grasa en la leche se muestra en la figura 3; se encontraron valores de significancia $(p<0.001)$ con correlaciones negativas entre CCS y el porcentaje de grasa en la leche en la primera porción durante las semanas 18 , 22 y 26 de lactancia, en la porción

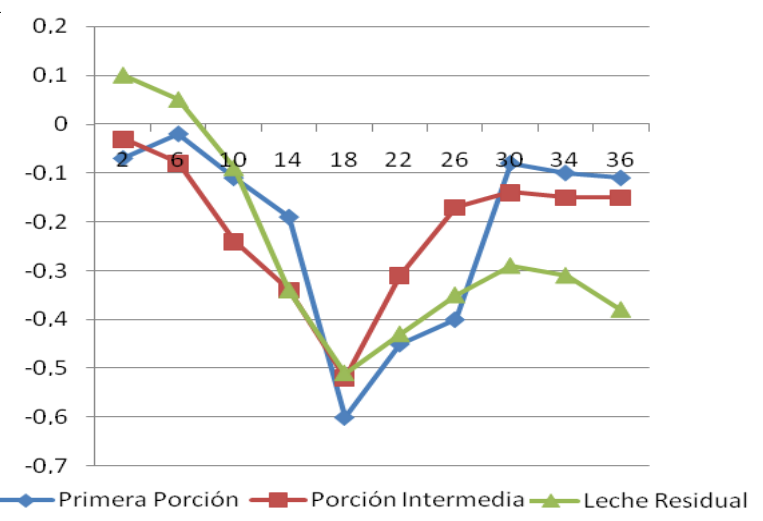

Figura 3. Correlación entre CCS y el porcentaje de grasa en la leche, semanas 2 a 36. 
intermedia, el porcentaje de grasa en las semanas 14, 18 y 22 de lactación y en la leche residual en las semanas $14,18,22$, 26,34 y 36 de lactancia.

Entre el CCS y el porcentaje de proteína (Figura 4.); los CCS tuvieron una correlación negativa $(p<0.05)$ con el porcentaje de proteína de la leche en la primera porción de las semanas 10,18 y 22 de lactación. Correlaciones negativas ( $p<0.01$ o $p<0.05$ ) también se encontraron en el CCS en el porcentaje de proteína en la muestra intermedia y en la leche residual de las semanas 10 y 18 de lactación.

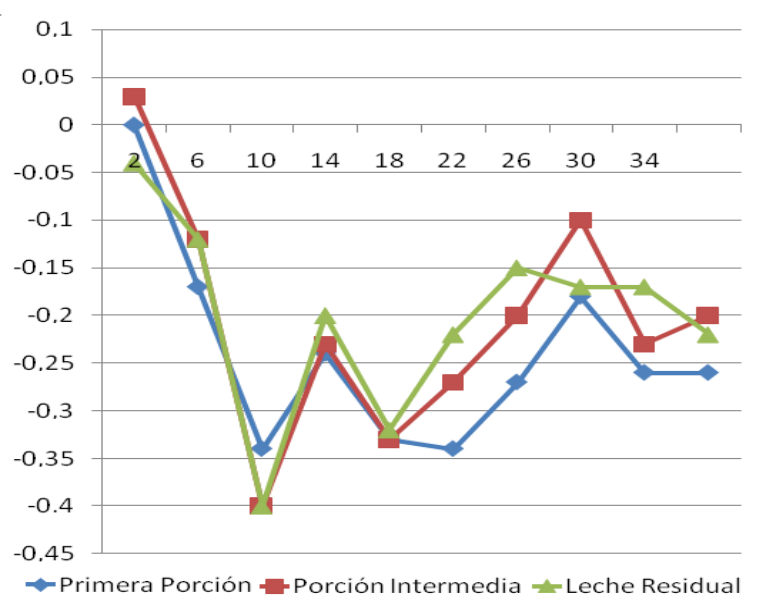

Figura 4. Correlación entre CCS y el porcentaje de proteína en la leche, semanas 2 a 36.

EI CCS y el porcentaje de sólidos no grasos (SNG) (Figura 5); mostraron una correlación negativa significativa entre el porcentaje de SNG en la primera muestra en la semana 10 $(p<0.01), 14(p<0.01), 18(<0.001), 22$

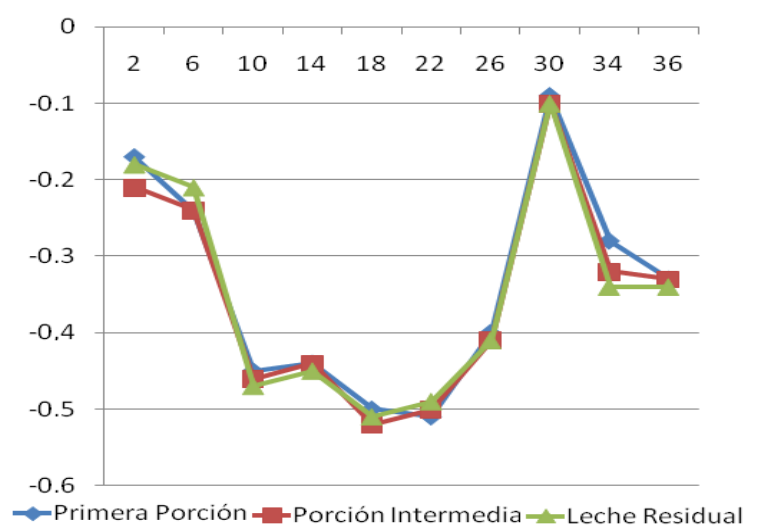

Figura 5. Correlacion entre CCS y solidos no grasos durante las semanas de lactación. $(p<0.001), 26(p<0.01)$ y $36(p<0.05)$ de lactancia. También se encontró una correlación negativa entre el CCS y el porcentaje de SNG en la muestra intermedia $y$ en la leche residual de las semanas 10 $(p<0.01), 14(p<0.01), 18(p<0.001), 22$ $(p<0.001), 26(p<0.01), 34(p<0.05)$ de lactancia.

\section{DISCUSIÓN}

Los resultados indicaron una alta significancia $(p<0.001)$ influyendo el sistema de cría de terneras, número de parto de las vacas, proporción de genes Holsten Friesian (HF), época de nacimientos, cuarto de la ubre, semana de la lactación, interacción entre el método de ordeño, interacción entre el sistema de cría y el conteo de células somáticas en las semanas 2 y 36 .

Como se esperaba los partos tienen una alta significancia $(p<0.001)$ influyendo en CCS; las vacas multíparas exceden a las vacas primíparas en RCS $(+18 \%)$. El resultado concuerda con estudios posteriores en los cuales fueron reportados incrementos de 5 veces debido a la infección por patógenos desde la primera hasta la sexta lactación (6-11).

En hatos lecheros bajo el programa DHIA, se encontró un incremento lineal de conteo celular con el número de lactancias (12); esto puede estar asociado con cambios en la susceptibilidad de infecciones por patógenos en lactaciones sucesivas.

En cuanto a la edad de la vaca; vacas viejas presentaron una mayor tendencia a contraer infecciones lo cual causa mayores daños en el tejido, comparado con vacas jóvenes; esto podria sugerir que las vacas viejas están más expuestas a patógenos frente a vacas jóvenes (13). Adicionalmente el número de partos en vacas viejas tiene levemente altos conteos de células somáticas frente a vacas jóvenes $(10,14)$.

Es interesante hacer notar que vacas $\mathrm{HF}$ con alto grado de pureza disminuyen significativamente los conteos de células somáticas $(p<0.001)$. Las vacas con $87.5 \%$ 
de pureza HF mostraron significancia $(p<0.001), 23 \%$ menos conteos células somáticas que $75 \%$ pureza HF de vacas cruzadas. Esto puede ser explicado por el efecto de dilución asociados con altas producciones con HF mejorado.

Una correlación entre CCS $(p<0.010$ $\mathrm{p}<0.001$ ) y los componentes de la leche (por ejemplo grasa, proteína y SNG) en las tres muestras de leche se encontraron en las semanas $10,14,18,22,26,34$ y 36 de la lactación con coeficiente de correlación (CC) entre -0.44 y -0.60. Esta relación entre grasa de leche y conteo de células somáticas coincide con la disminución en la producción de grasa cuando se tienen resultados altos con el Test de California Mastitis (CMT), infecciones subclínicas y altos CCS respectivamente $(10,15,16)$. Estos cambios resultan de la reducción en la actividad de síntesis de los componentes de la leche en ubres infectadas (10).

Los resultados mostraron correlaciones negativas entre conteo de células somáticas y proteína en leche, la producción de proteína sintetizada en la glándula mamaria disminuye con la mastitis (5); coincidiendo con otros estudios los cuales hallaron una disminución de proteína con incremento del conteo celular en vacas lecheras $(2,17,18)$. Sin embargo, otros reportes han mostrado resultados contradictorios (19), apreciándose un pequeño incremento del contenido de proteína en la lactación (aproximadamente desde 0.06 hasta $0.12 \%$ puntos de proteína), lo cual puede ser asociado en un incremento de la presencia de elementos de sangre en la leche a través de la reacción inflamatoria (20).
Es claro que el sistema de amamantamiento restringido, disminuye significativamente los CCS y mejora sustancialmente la sanidad de la ubre. En el sistema de AR, la cría succiona la leche residual por lo cual absorbe los patógenos de la mastitis; en consecuencia, vacas en sistema de CA mostraron altos conteos celulares al compararlas con AR, especialmente durante las semanas 2 hasta 10 de lactación. Vacas en sistema de CA mostraron altos conteos celulares al compararlas con AR, especialmente durante las semanas 2 hasta 10 de lactación.

En general, vacas mantenidas con amamantamiento restringido en el sistema Altiplano Boyacense, mostraron mejores perfiles en sanidad de la ubre y mayor cantidad de leche para la venta anual por que se alargan las lactancias. Altos conteos de células somáticas coinciden con disminución en la producción de grasa, estos cambios resultan de la reducción en la actividad de síntesis de los componentes de la leche.

Los resultados mostraron correlaciones negativas entre conteos de células somáticas y proteína en la leche, la producción de proteína sintetizada en la glándula mamaria disminuye con la mastitis.

En conclusión, el sistema de amamantamiento, el número de partos, la proporción genética, la época de nacimientos, el cuarto de la ubre, la semana de lactancia y el sistema de ordeño interactúan con el conteo de células somáticas en forma significativa entre las semanas 2 y 36 de lactancia.

\section{REFERENCIAS}

1. Berning LM, ShooK GE. Interlaboratory Collaborative Study on the Kjeldahl reference Determination in cows according to ISO 8968. Dairy Sustainability Bulletin 2002; 75:1810-1818.
2. Philpot WN, Nickerson $\mathrm{H}$. Influence of subclinical mastitis on milk production and milk composition. J Dairy Sci 2007; 50: 978-988.

3. Linzell J L, Peaker M. Mechanism of Milk secretion. Physiol Rev 2001; 51(3):564-597. 
4. Reichmuth J, Zeidler $\mathrm{H}$, Tolle A, Heeschen W. Zum Einfluss subklinischer Mastitiden auf die Milchleistung des Rindes. Berl Mûnch Tierarztl Wschr 2000; 83:26-30.

5. Raubertas RF, Shook G.E. Relationship between lactation measures of somatic cell concentration and milk yields. J Dairy Sci 2002; 65: 419-425.

6. Ali AK, Shook GE. An optimum transformation for somatic cell cocentration in milk. J Dairy sci 2000; 63: 487-490.

7. Banos G, Shook GE. Genotype by enviroment interaction and genetic correlations among parities for somatic cell count and milk yield. J dairy sci 2000 ; 73:2562-2573.

8. Emanuelson UB, Danell S, Philipsson J. Studies on somatic cell counts in milk from Swedish dairy cows. II. Estimates of genetic parameters of monthly test-day results. Acta agric Scand 2004; 34:45-52.

9. Hortet $\mathrm{P}$, Beaudeau F, Seegers H, Fourichon C. Reduction in milk yield associate with somatic cell counts up to $600.000 \mathrm{cel} / \mathrm{ml}$ in French Holstein cows without clinical mastitis. Livest Prod Sci 2007; 61:33-42.

10. Schultzs MM, Hansen LB, Steuernagel GR, Luck LA. Genetic parameters for somatic cells, protein and fat in milk of Holstein. J Dairy sci 2005; 73: 484-493.

11. Pappe M, Duenas JM, Wetterman RP, Douglass LW. Effect of intramamary infections and parity on calf weaning weigh and milk quality in beef cows. J Animal Sci 2000; 78: 2508 - 2514.

12. Smith AM, Chesworth J M, Rodway RG. Use of Laurell electrophoresis for the quantitative measurement of albumin in mastitis milk. J Dairy Res 2005; 46: 547-550.
13. Dunham JR, Rodway RG. Mammary gland healt and milk quality: Using the somatic cell count profile. In: 1996 heart of America Dairy Management conference. Kansas city; MO. 2005. 34 - 39

14. Reneau JK, Henderson GD. Effective use of Dairy Ferd and improvement somatic cell counts in mastitis control. J Dairy Sci 2006; 69: 1708-1720.

15. Brolund L, Luedecke LO. Cell counts in bovine milk, causes of variation and applicability for diagnosis of subclinical mastitis. Acta Vet Scand 2005; 80(Suppl 27): (Abstr).

16. Ashworth US, Foster TL. Relationship between California mastitis test reaction and composition of milk from opposite quartes. J Dairy Sci 2003; 50: 1078-1082.

17. Dentine $\mathrm{MH}, \mathrm{McDAniel}$ BT. Evidence for nonlinearity in the relationship between milk and fat yields and the logarithm of the geometric mean of somatic cell counts. J Dairy Sci 2003; 66(supp 1): 112.

18. Haenlei GF, Schultz LH, Hansen LR. Relation of milk fat-depressing rations and subclinical mastitis to milk proteins. J Dairy Sci 2003; 51: 535-542.

19. Houben EH, Dijkhuizen AA, Van Arendonk JA, Huirne RB. Short and long-term production losses and repeatability of clinical mastitis in dairy cattle. J Dairy Sci 2003; 76: 2561-2578.

20. Larson BL, Hearyc HL. Inmonoglobulin productions and transport by the mammary gland. J Dairy Sci 2000; 63:665-671. 